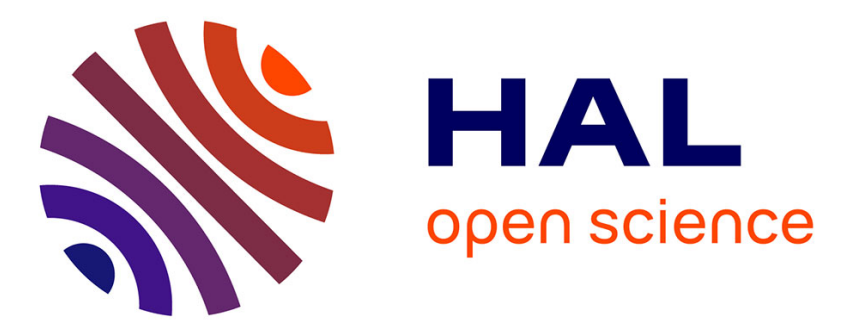

\title{
A self-assembled tetrathiafulvalene box
}

Serhii Krykun, Vincent Croué, Olivier Alévêque, Eric Levillain, Magali Allain, Cécile Mézière, Vincent Carré, Frédéric Aubriet, Zoia Voïtenko, Sébastien Goeb, et al.

\section{- To cite this version:}

Serhii Krykun, Vincent Croué, Olivier Alévêque, Eric Levillain, Magali Allain, et al.. A self-assembled tetrathiafulvalene box. Organic Chemistry Frontiers, 2021, 8 (5), pp.883-890. 10.1039/D0QO01543A . hal-03433142

\section{HAL Id: hal-03433142 \\ https://hal.science/hal-03433142}

Submitted on 26 Nov 2021

HAL is a multi-disciplinary open access archive for the deposit and dissemination of scientific research documents, whether they are published or not. The documents may come from teaching and research institutions in France or abroad, or from public or private research centers.
L'archive ouverte pluridisciplinaire HAL, est destinée au dépôt et à la diffusion de documents scientifiques de niveau recherche, publiés ou non, émanant des établissements d'enseignement et de recherche français ou étrangers, des laboratoires publics ou privés. 


\section{A self-assembled tetrathiafulvalene box}

Serhii Krykun, ${ }^{\mathrm{a}, \mathrm{b}}$ Vincent Croué, $^{\mathrm{a}}$ Olivier Alévêque, ${ }^{\mathrm{a}}$ Eric Levillain, ${ }^{a}$ Magali Allain, ${ }^{a}$ Cécile Mézière, ${ }^{a}$ Vincent Carré, ${ }^{c}$ Frédéric Aubriet, ${ }^{c}$ Zoia Voïtenko, ${ }^{b}$ Sébastien Goeb, ${ }^{* a}$ Marc Sallé*a

\section{Introduction}

The dimerization of conjugated radical-cations constitutes an appealing interaction of the supramolecular tool-box, which has known a strong recent interest. ${ }^{1-4}$ Interestingly, the latter can be controlled through a redox stimulation, as demonstrated with the prototypal electroactive cases of tetrathiafulvalene (TTF) or bipyridinium derivatives. Oxidation in solution of TTF derivatives ${ }^{5,} 6$ into the corresponding $\pi$-dimer species $\left(\mathrm{TTF}^{\bullet+}\right)_{2}$ has been characterized in very specific cases, i.e. highly concentrated solutions at low temperature, 7,8 redox-active units confined in a molecular cavity, ${ }^{9-12}$ covalently preorganized poly-TTF systems, ${ }^{13-22}$ or stabilization of TTF units in interlocked structures. ${ }^{1,23}$

To get a better control over the experimental parameters driving the radical-pairing interaction, there is a need to develop new molecular models. In this context, designing bis(TTF) architectures with two preorganized facing TTF units, prone to stack, is of interest notably if the intramolecular inter-TTF distance can be tuned. A similar approach was recently developed with success in the case of flexible viologen cyclophanes, through controlling the linker length between both redox units. ${ }^{24-26}$

To the best of our knowledge, only one organic macrocycle ${ }^{27}$ featuring two facing TTF moieties has been described so far. ${ }^{28}$ This electron-rich bis(TTF)derivative, prepared in several steps through covalent synthesis, was designed to afford a distance of $c a$. 7A between both TTF plans in order to bind planar electron-poor guests in a sandwich-like manner.
On the other hand, macrocyclic metalla-rings can be prepared in one step and in excellent yields through the coordinationdriven self-assembly strategy between polytypic ligands and specific metal complexes. ${ }^{29-51}$ For instance, this approach has allowed to target electro-active assemblies. ${ }^{52-58}$ We have contributed to this field by synthesizing a large number of redox-active supramolecular cavities incorporating electronrich dithiolylidene units, such as with extended-TTF derivatives ${ }^{59-64}$ or very recently, S-rich fluorene derivatives. ${ }^{65-67}$ Despite well-defined redox properties, only two examples of discrete metalla-assemblies based on the parent TTF framework have been described so far. ${ }^{68,69}$ They were obtained upon selfassembling a tetratopic TTF-based ligand bearing four pyridyl units ( $\left.\operatorname{TTF}(\mathbf{P y r})_{4}\right)$, with either a cis-blocked $\mathrm{M}(\mathrm{II})$ complex $(\mathrm{M}=$ $\mathrm{Pd}$ or $\mathrm{Pt}$ ), ${ }^{69}$ or a bis-Ruthenium one $\mathbf{R u O x}^{68}$ (Scheme 1). In the latter case, a $\mathrm{M}_{8} \mathrm{~L}_{2}$ assembly was obtained in good yields, for which two TTF units are facing each other. On the contrary, a $\mathrm{M}_{4} \mathrm{~L}$ metalla-plate (i.e. one ligand aassociated to two bisRuthenium complexes) was obtained upon mixing $\operatorname{TTF}(\mathbf{P y r})_{4}$ with the longer bis-Ruthenium complex RuBenz (Scheme 1). ${ }^{68}$ Such a difference is due to the respective Ru-Ru distance in both

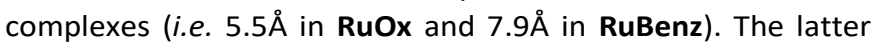
value well matches for the coordination of two adjacent pyridyl units in $\operatorname{TTF}(\mathbf{P y r})_{4}(\mathrm{Npyr} \cdots \mathrm{Npyr}=6.7 \AA ̊ \AA)$, favoring the $\mathrm{M}_{4} \mathrm{~L}$ discrete structure (Scheme 1 and Figure 1). Driving the self-assembly to a new $M_{8} L_{2}$ TTF-box for which two TTF units are forced to face each other, needs therefore a mismatch between both Npyr $\cdots$ Npyr and Ru $\cdots$ Ru distances. This can be achieved through changing the ligand size (i.e. the distance between two Npyr atoms) or the bis-Ruthenium complex (i.e. the distance between two Ru atoms).

We present hereafter the coordination-driven assembling of a new $M_{8} L_{2}$ TTF-box using the new enlarged TTF-based ligand TTF(PhPyr) ${ }_{4}$ and the bis-Ruthenium ${ }^{70}$ complex RuNaph (Scheme 1). The interaction between both facing redox units in this system is investigated in solution. This study shows that both TTF units dimerize intramolecularly when oxidized to the radical-cation state, thanks to the rigidity of the assembly. 


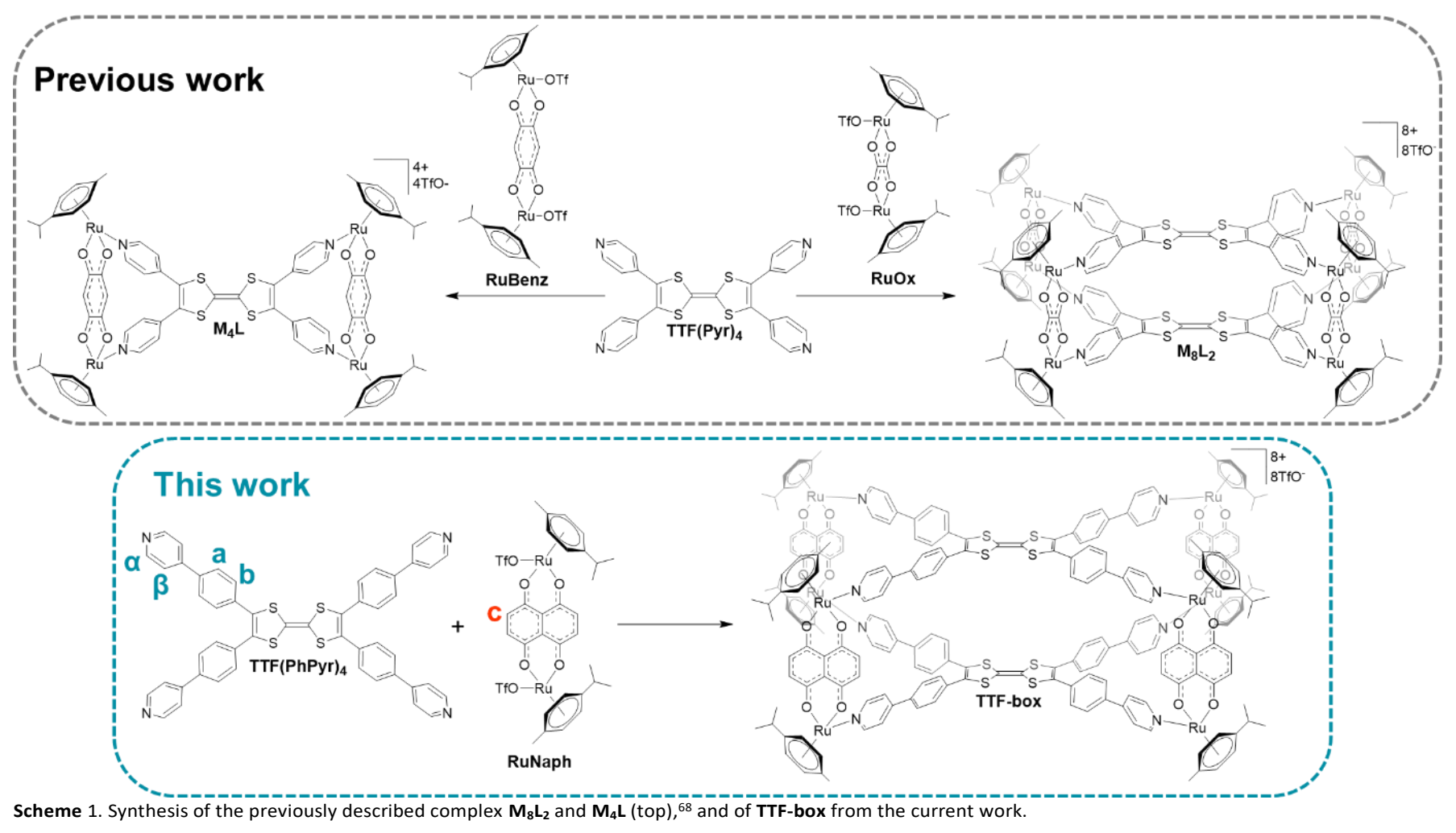

\section{Results and discussion}

We designed the tetratopic ligand TTF(PhPyr $)_{4}$ which differs from $\operatorname{TTF}(\mathbf{P y r})_{4}$ by the presence of a paraphenylene spacer between the redox and coordinating units. Importantly, this design results in a much longer separation between adjacent Npyr atoms, prone to change drastically the reaction with a bisRuthenium complex of a given length $\left(M_{8} L_{2}\right.$ vs $M_{4} L$ selfassemblies). The new ligand TTF(PhPyr $)_{4}$ was synthesized in 86\% yield using a Palladium-catalyzed $\mathrm{C}-\mathrm{H}$ activated tetraarylation, ${ }^{71}$ starting from the commercially available TTF and (4-bromophenyl)pyridine. ${ }^{72}$ This yield is remarkable given the formation a four new $\mathrm{C}-\mathrm{C}$ bonds along this process. Single crystals of ligand TTF(PhPyr $)_{4}$, suitable for a X-ray diffraction study, were obtained by slow evaporation of a dichloromethane/methanol mixture. X-ray data show a significant disorder of the phenyl units through rotation around the TTF-Pyr axis (Figure 1). The molecule is contained in a 12.8 $x 19.3 \AA$ rectangle, as defined by the four Npyr atoms. These values can be compared with those observed for $\operatorname{TTF}(\mathbf{P y r})_{4}(6.7$ $x$ 13.1A). ${ }^{69}$ In particular the distance between adjacent NPyr atoms in $\mathbf{T T F}(\mathbf{P h P y r})_{4}$ appears significantly higher than in $\operatorname{TTF}(\mathbf{P y r})_{4}(12.8 \AA \AA$ vs $6.7 \AA ̊$ ) as well as when compared to the Ru$\mathrm{Ru}$ distances for all the bis-Ruthenium complexes studied (Scheme 1). Such mismatching of the distances between the NPyr coordinating units on one hand, and both metals of the bis-Ruthenium complex on the other hand, is prone to favor the formation of the desired $M_{8} L_{2}$ self-assemblies. Reaction of $\operatorname{TTF}(\mathbf{P h P y r})_{4}$ with the bis-Ruthenium complex RuNaph $\left(\mathrm{d}_{\mathrm{Ru}-\mathrm{Ru}}=\right.$

a)

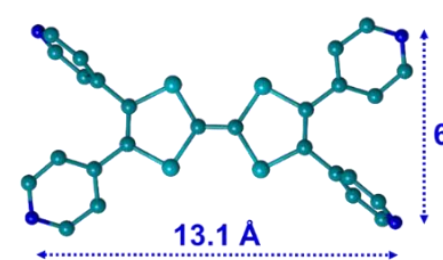

$6.7 \AA$

b)

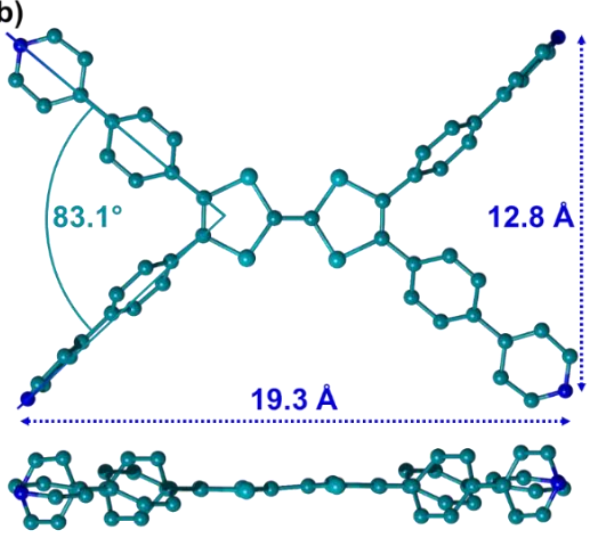

Fig. 1. X-ray crystal structures of a) $\operatorname{TTF}(\mathbf{P y r})_{4}$ and b) $\operatorname{TTF}(\mathbf{P h P y r})_{4}$ ligands.

8.4 Å) in acetone was followed by ${ }^{1} \mathrm{H}$ NMR spectroscopy. After one night, the resulting spectrum shows well defined signals, suggesting the formation of a discrete self-assembled system (Figure 2). The $\alpha$ pyridyl protons signals as well as those of the paraphenylene spacer are upfield shifted upon coordination to 
the metal center. Occurrence of a single discrete structure is confirmed by a ${ }^{1} \mathrm{H}$ DOSY NMR experiment, for which a single set of aligned signals is observed. The corresponding diffusion coefficient $\left(D=4.75 \times 10^{-10} \mathrm{~m}^{2} . \mathrm{s}^{-1}\right)$ allows to estimate a hydrodynamic radius of $r_{H}=15 \AA$ calculated from the Stokes-

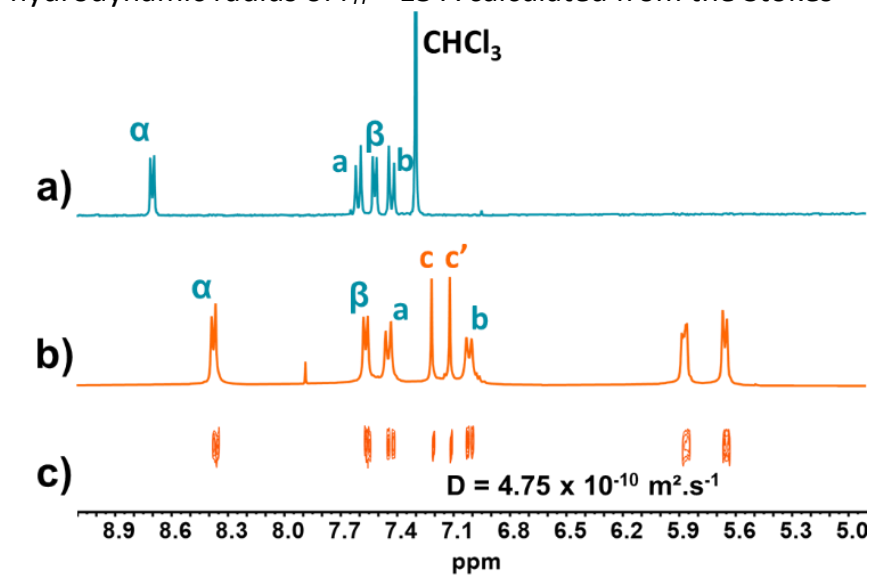

Fig. 2. (a) ${ }^{1} \mathrm{H}$ NMR (aromatic region) of ligand $\mathrm{TTF}(\mathbf{P h P y r})_{4}$ in $\mathrm{CDCl}_{3}$, (b) TTF-box in Acetone- $d_{6}$ and $(c)^{1} \mathrm{H}$ DOSY NMR corresponding to $(b)$.

Einstein equation, ${ }^{73}$ a value which is in agreement with the expected $M_{8} L_{2}$ species.

An FTCIR-MS analysis was carried out and confirms the formation of the $M_{8} L_{2}$ TTF-box, as shown by the characteristic ions $\left[\left(\mathrm{TTF}(\mathbf{P h P y r})_{4}\right)_{2}(\text { RuNaph })_{4}\right.$, 5TfO- $^{-3+}(\mathrm{m} / \mathrm{z}=1671.4093)$ and $\left[\left(\mathrm{TTF}(\mathrm{PhPyr})_{4}\right)_{2}(\text { RuNaph })_{4}, 4 T f \mathrm{TO}^{-}\right]^{4+}(\mathrm{m} / \mathrm{z}=1216.3185)$ (Figure S7).

Single-crystals were obtained by diffusion of methyl-tert-butyl ether into a solution of TTF-box in methanol (Figure 3 ) and the $\mathrm{X}$-ray diffraction structure of the TTF dimeric structure could be solved. Two independent molecules are present in the crystal. From these data, a length of $c a .37 \AA$

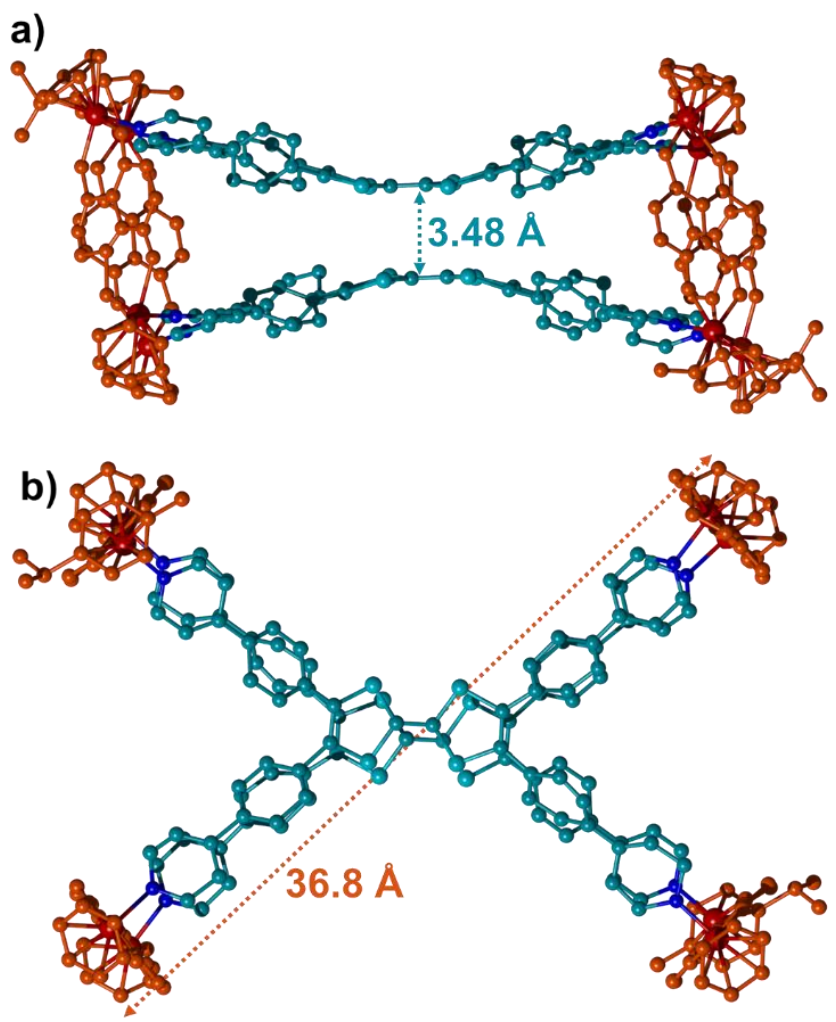

Fig. 3. X-ray structure of TTF-box, lateral view (a), top view (b). Hydrogens, anions and solvent molecules are omitted for clarity.

was found for the largest diagonal of TTF-box, a value which satisfactorily correlates with the calculation extracted from the DOSY ${ }^{1} \mathrm{H}$ NMR study. The most striking feature of this structure relies on the close distance between both facing TTF units within the dimeric structure. A short distance of $3.48 \AA$ is observed between both central $C=C$ bonds of two opposite TTF units, and S ‥ S distances as low as $3.83 \AA$ for the smallest. These values are significantly smaller than the Ru-Ru distance in each of the four lateral pillars (8.38 $\AA$ ), meaning that the TTF dimeric structure is collapsed and fills the space between both TTF units. This observation means that a certain degree of conformational flexibility exists in the TTF framework, though there is no sp3 C atom in the entire system. In particular, one of the TTF units undergoes a bending of $20^{\circ}$ around the S $\cdots S$ axis of one 1,3dithiol ring. Though the design and size of this metallacage suggests the possibility to intercalate one planar electron-poor guest in a sandwich mode, all attempts failed, probably because of the close contacts occurring between both TTF panels. This observation is consistent with the study of J. Becher et al. ${ }^{28}$ The electrochemical properties of $\mathbf{T T F}(\mathbf{P h P y r})_{\mathbf{4}}$ were studied (Figure 4a). and compared to those of $\operatorname{TTF}(\mathbf{P y r})_{4}{ }^{69}$ and the tetrakis(methylpyridinium) derivative of $\mathbf{T T F}(\mathbf{P h P y r})_{4}$, i.e. compound TTF(PhPyrMe) ${ }_{\mathbf{4}}$ (see SI). The latter can be considered as a model compound, reminiscent of ligand TTF(PhPyr $)_{4}$ when 

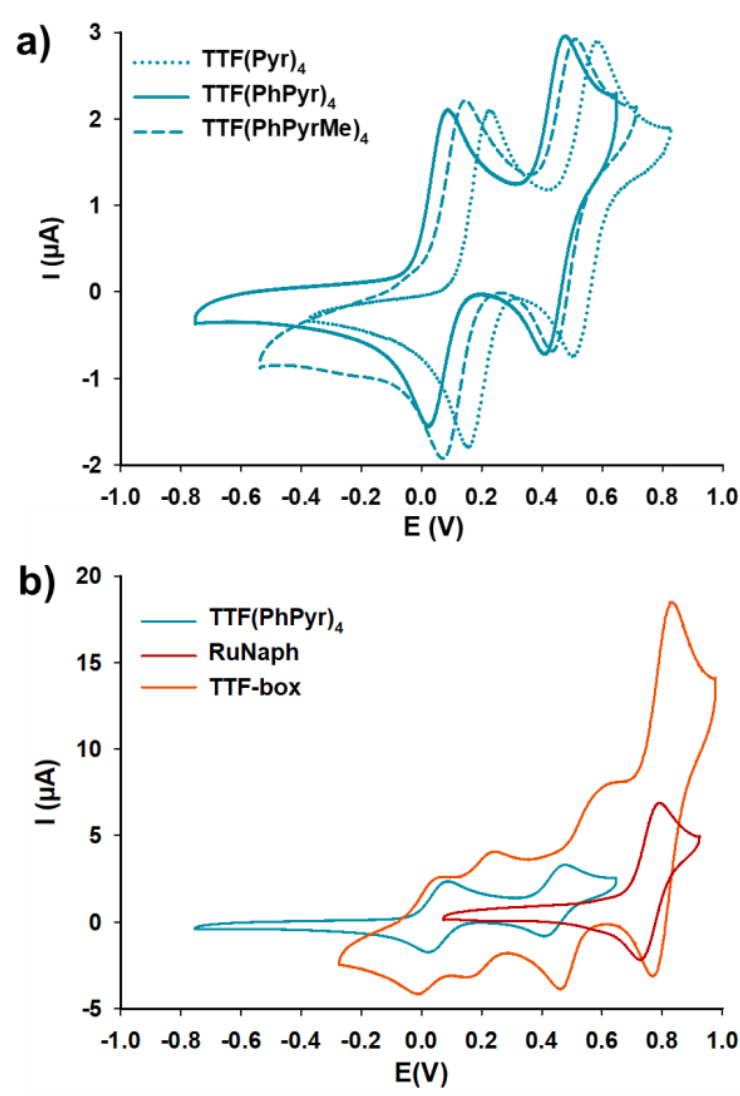

Fig. 4. Cyclic voltammetry in $\mathrm{CH}_{3} \mathrm{CN} / \mathrm{CH}_{2} \mathrm{Cl}_{2} 1 / 1\left(\mathrm{C}=1 \mathrm{mM}, \mathrm{nBu}_{4} \mathrm{NPF}_{6}(0,1 \mathrm{M})\right), 100$ $\mathrm{mV} . \mathrm{s}^{-1}$, glassy carbon, vs Fc/Fc ${ }^{+}$of $\operatorname{TTF}(\mathbf{P h P y r})_{4}{ }^{*}{ }^{*} \operatorname{TTF}(\mathbf{P h P y M e})_{4}$, and $\operatorname{TTF}(\mathbf{P y r})_{4}$ (a) and of TTF-box, compared to the starting ligand $\mathbf{T T F}(\mathbf{P h P y r})_{4}$ and the bisRuthenium complex RuNaph (b). * For solubility reasons $\operatorname{TTF}(\mathbf{P h P y})_{4}$ was recorded in $\mathrm{CH}_{2} \mathrm{Cl}_{2}$.

the latter is engaged in a coordination bond as it is the case in TTF-box. The pyridyl groups quaternization was carried out upon treating TTF(PhPyr) ${ }_{4}$ with methyl iodide in DMF, followed by an anion exchange with $\mathrm{KPF}_{6}$. The ligand TTF(PhPyr $)_{4}$ shows two reversible oxidation waves $\left(E_{1}{ }^{o x}=0.08 \mathrm{~V}\right.$ and $E_{2}{ }^{\text {ox }}=0.48 \mathrm{~V}$ vs $\mathrm{Fc} / \mathrm{Fc}^{+}$) corresponding to two successive one-electron oxidations to the radical-cation and dication states, as usually observed for TTF derivatives. It is worth noting that these oxidations occur at significantly lower potentials compared to $\operatorname{TTF}(\mathbf{P y r})_{4}$ ones $\left(\mathrm{E}_{1}{ }^{\mathrm{ox}}=0.22 \mathrm{~V}\right.$ and $\mathrm{E}_{2}{ }^{\mathrm{ox}}=0.58 \mathrm{~V}$ vs $\left.\mathrm{Fc}^{\mathrm{o}} / \mathrm{Fc}^{+}\right)$. This difference can be explained by the presence of the phenyl spacer which isolates the pyridyl groups from the redox-active
TTF core, thereby attenuating the withdrawing inductive effect of Npyr atoms. On this basis, compound TTF(PhPyr $)_{4}$ exhibits a high $\pi$-donating ability and appears appropriate for generating electron-rich discrete assemblies. The corresponding tetrapyridinium salt $\operatorname{TTF}(\mathrm{PhPyrMe})$ shows redox waves $\left(\mathrm{E}_{1}{ }^{\mathrm{ox}}=\right.$ $0.14 \mathrm{~V}$ and $\mathrm{E}_{2}{ }^{\mathrm{ox}}=0.51 \mathrm{~V} v \mathrm{Fc} / \mathrm{Fc}$ ) which are anodically shifted when compared to $\mathbf{T T F}(\mathbf{P h P y r})_{4}$, as expected from the positively charges nitrogen atoms.

Interestingly, under the same conditions, TTF-box exhibits a splitting of the first oxidation process into two reversible waves $\left(E_{1}{ }^{0 x}=0.04 \mathrm{~V}\right.$ and $E_{2}{ }^{o x}=0.24 \mathrm{~V}$ vs $F c / F c^{+}$, Figure $\left.4 b\right) .{ }^{74}$ This observation is assigned to the successive formation of the mixed-valence dimer $\left((\mathrm{TTF})_{2}\right)^{\bullet+}$ and of the corresponding $\pi$ dimer $\left(\mathrm{TTF}^{\bullet+}\right)_{2 .}{ }^{14}, 16,18$ Such phenomenon is explained by the very close distance between both facing TTF subunits in TTFbox, prone to strongly interact upon oxidation. A third reversible oxidation process, located at $\mathrm{E}_{3}{ }^{\mathrm{ox}}=0.60 \mathrm{~V}$ vs $\mathrm{Fc} / \mathrm{Fc}^{+}$ and anodically shifted compared to TTF(PhPyrMe) because of coulombic repulsions, is assigned to the formation of the dication state for each TTF unit. The last reversible oxidation process is observed at $\mathrm{E}_{4}{ }^{\mathrm{ox}}=0.83 \mathrm{~V} v \mathrm{Fc} / \mathrm{Fc}^{+}$and is ascribed to one $\mathrm{Ru}(\mathrm{II}) \rightarrow \mathrm{Ru}(\mathrm{III})$ oxidation per bimetallic pillar, as shown from comparison with RuNaph (Figure 4b). Finally, an additional irreversible process attributed to the oxidation of the second metal cation on each RuNaph pillar is located at $E_{5}{ }^{\text {ox }}=1.21 \mathrm{~V} v \mathrm{~s}$ $\mathrm{Fc} / \mathrm{Fc}^{+}$(Figure S8)..$^{75}$ On this basis, it is important to highlight that: $i)$ the charge on TTF-box can be monitored in a fully reversible manner from $8+(E=-0.2 \mathrm{~V})$ to $16+(E=+1.0 \mathrm{~V})$, ii) a remarkably high charge state of $20+$ is reached at $E=1.2 \mathrm{~V}$ and iii) the self-assembled TTF-box remains stable upon repeated cycles within this window of potentials. Intercalation of polyaromatic guests (i.e. pyrene or perylene) could not be detected along those electrochemical experiments (no variation of redox potentials). This may be explained by the presence of competitive counter anions that may obstruct the cavity when TTF-box is oxidized. ${ }^{60}$

Spectroelectrochemistry experiments were led to get a better insight on the electronic interactions occurring between both TTF moieties in the self-assembly. They were carried out on TTF-box as well as on RuNaph and the corresponding tetracationic salt TTF(PhPyrMe) $)_{4}$. The UV-vis spectra of the three compounds are shown in Figure 5a. The tetrakis(pyridinium) salt TTF(PhPyrMe) $)_{4}$ exhibits two strong absorption bands at $\lambda=325 \mathrm{~nm}\left(\varepsilon=41100 \mathrm{I} . \mathrm{mol}^{-1} \cdot \mathrm{cm}^{-1}\right)$ and $\lambda=460 \mathrm{~nm}\left(\varepsilon=4200 \mathrm{I} \cdot \mathrm{mol}^{-1} \cdot \mathrm{cm}^{-1}\right)$, assigned to $\pi-\pi^{*}$ 

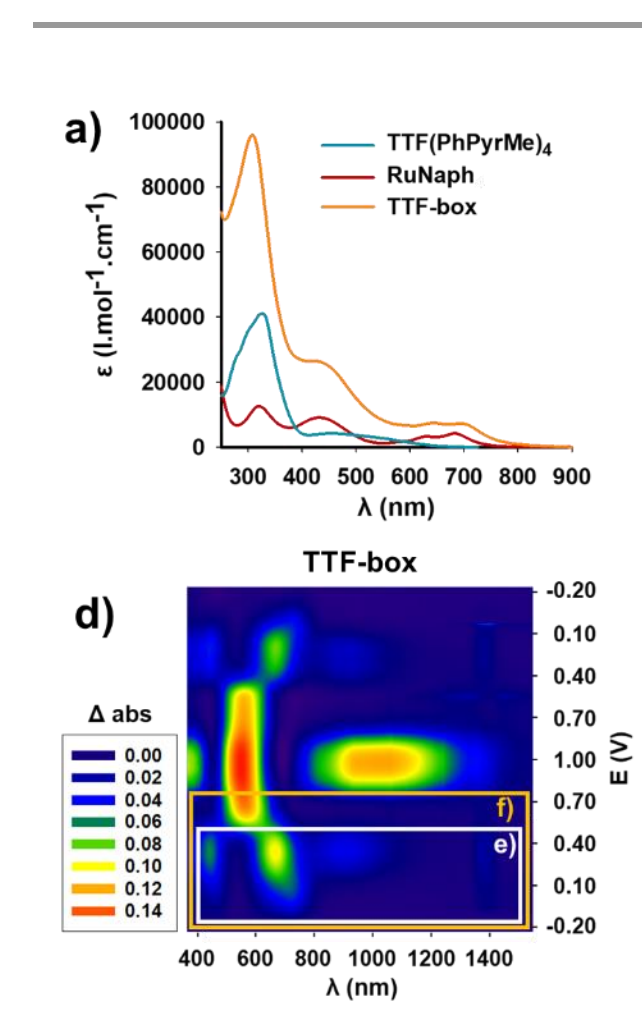
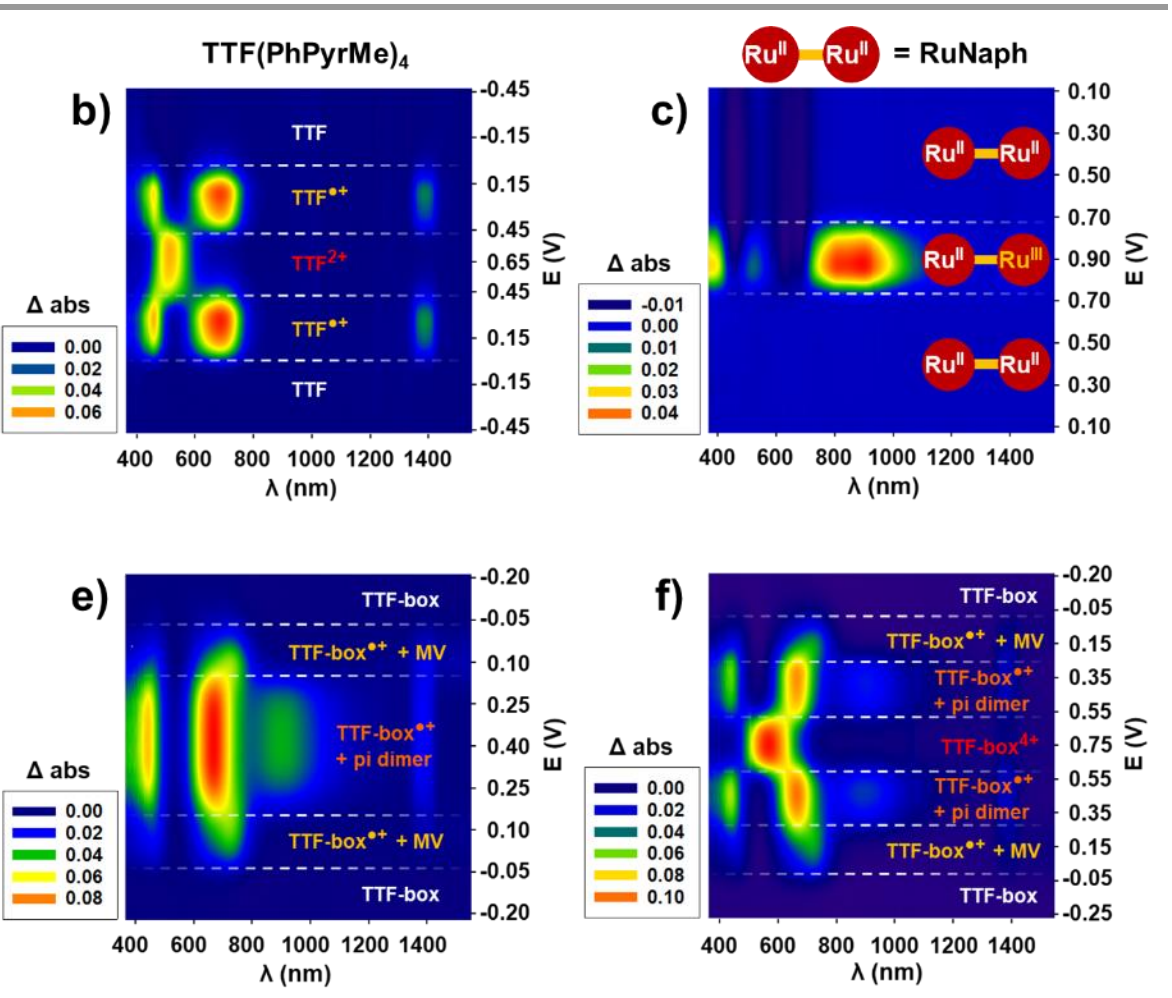

Fig. 5. UV-vis absorption spectra of TTF(PhPyrMe) $)_{4}$, RuNaph and TTF-box in $\mathrm{CH}_{3} \mathrm{CN} / \mathrm{CH}_{2} \mathrm{Cl}_{2} 1 / 1\left(\mathrm{C}=5 \times 10^{-5} \mathrm{M}\right)$ (a). Absorption spectroelectrochemistry experiment in thin layer conditions $(\sim 50 \mu \mathrm{m})$ during a cyclic voltammetry experiment in $\left.\mathrm{CH}_{3} \mathrm{CN} \mathrm{CH}_{2} \mathrm{Cl}_{2} 1 / 1\left(\mathrm{C}=1 \mathrm{mM}, \mathrm{n}-\mathrm{Bu}_{4} \mathrm{NPF} \mathrm{F}_{6}(0,1 \mathrm{M})\right), 20 \mathrm{mV} . \mathrm{s}^{-1}, 20^{\circ} \mathrm{C}\right)$ of $\mathrm{TTF}(\mathrm{PhPyrMe})_{4}(\mathrm{~b})$, RuNaph (c) and TTF-box in the $-0.20-1.00 \mathrm{~V}$ range (d), oxidation and reduction scan limited to TTF radical cation, i.e. in the $-0.20-0.40 \mathrm{~V}$ range (e) and finally oxidation and reduction scan limited to TTF dication, i.e. $-0.25-0.75 \mathrm{~V}$ range $(\mathrm{f}) ; \mathrm{z}$ axis $=$ variation of absorbance $\Delta(\mathrm{Abs}), \mathrm{MV}=\mathrm{mixed}$ valence.

transitions and intra-ligand charge transfer respectively. The RuNaph complex exhibits main absorptions at $\lambda=320 \mathrm{~nm}(\varepsilon=$ $\left.12600 \mathrm{I} . \mathrm{mol}^{-1} \cdot \mathrm{cm}^{-1}\right)$ and $\lambda=430 \mathrm{~nm}\left(\varepsilon=9100 \mathrm{I} . \mathrm{mol}^{-1} \cdot \mathrm{cm}^{-1}\right)$, which correspond to the intra-ligand charge transfer in naphthalene and cymene, and minor absorptions at $\lambda=630 \mathrm{~nm}(\varepsilon=3300$ I. $\left.\mathrm{mol}^{-1} . \mathrm{cm}^{-1}\right)$ and $\lambda=682 \mathrm{~nm}\left(\varepsilon=4200 \mathrm{I} . \mathrm{mol}^{-1} \cdot \mathrm{cm}^{-1}\right)$, that correspond to the metal-ligand charge transfer due to the coordination with naphthalene and cymene. ${ }^{76}$ Finally, thespectrum of TTF-box essentially corresponds to the sum of the above respective contributions of $\operatorname{TTF}\left(\mathrm{PhPyrMe}_{4}\right.$ and RuNaph $\left(\lambda=305 \mathrm{~nm}\left(\varepsilon=96200 \mathrm{I} \cdot \mathrm{mol}^{-1} \cdot \mathrm{cm}^{-1}\right), 435 \mathrm{~nm}(\varepsilon=26\right.$ $\left.200 \mathrm{I} . \mathrm{mol}^{-1} . \mathrm{cm}^{-1}\right), 645 \mathrm{~nm}\left(\varepsilon=7900 \mathrm{I} . \mathrm{mol}^{-1} . \mathrm{cm}^{-1}\right)$ and $695 \mathrm{~nm}(\varepsilon$ $\left.=7500 \mathrm{I} \cdot \mathrm{mol}^{-1} \cdot \mathrm{cm}^{-1}\right)$ ) which is typical for such systems. ${ }^{77}$

The spectroelectrochemistry experiments were carried out upon monitoring the variation in absorbance, $\Delta(A b s)$, recorded in the UV-VIS-NIR region, while performing a cyclic voltammetry of a millimolar solution of the compound under study (0.1 M nBu $\mathrm{NPF}_{6} / \mathrm{CH}_{3} \mathrm{CN}-\mathrm{CH}_{2} \mathrm{Cl}_{2}$ 1/1) in thin layer conditions (TLCV experiment - thickness around 50 $\mu \mathrm{m}$ ) (Figure $5 b-f)$. The TTF(PhPyrMe $)_{4}$ pyridinium voltabsorptogram shows an increase of absorption upon formation of $\operatorname{TTF}^{\bullet+}(\lambda=460$ and $695 \mathrm{~nm})$ and $\operatorname{TTF}^{2+}(\lambda=520 \mathrm{~nm})$ at respectively $E_{1}{ }^{\mathrm{ox}} \simeq 0.20 \mathrm{~V}$ and $\mathrm{E}_{2}{ }^{\mathrm{ox}}=0.65 \mathrm{~V}$ vs Fc/Fc (Figure $5 \mathrm{~b}$ ). ${ }^{78,79}$ The oxidation of NaphRu $\left(\mathrm{Ru}^{\prime \prime} \rightarrow \mathrm{Ru} \mathrm{u}^{\mathrm{III}}\right)$ is characterized by the increase of distinctive bands around $375 \mathrm{~nm}, 525 \mathrm{~nm}$ (weak) and $900 \mathrm{~nm}$ (Figure 5c). The spectroelectrochemical spectrum of TTF-box recorded from $E=$ -0.20 to $1.00 \mathrm{~V}$ (Figure $5 \mathrm{~d}$ ), exhibits some differences compared to the superimposition of $\mathrm{TTF}\left(\mathrm{PhPyrMe}_{4}\right.$ and RuNaph contributions, as expected from the interaction occurring between both TTF units. A main difference concerns the region related to the first TTF oxidation step $(-0.05 \mathrm{~V}<\mathrm{E}<0.40 \mathrm{~V})$, for which additional absorption bands are detected (Figure $5 e$ ). At the very beginning of TTF-box first oxidation, spectral signatures are observed at $\lambda=465$ and $725 \mathrm{~nm}$, which are assigned to the radical-cation state (TTF-box ${ }^{\circ+}$ ) by analogy with above observations from $\operatorname{TTF}(\text { PhPyrMe })_{4} \cdot{ }^{80}$ As in CV experiments (Figure $4 \mathrm{~b}$ ), a second close one-electron transfer occurs at $E^{\circ \mathrm{X}} \simeq 0.30 \mathrm{~V}$. The latter is assigned to the formation of the $\pi$-dimer state $\left(\right.$ TTF-box $\left.{ }^{(\bullet+)} \mathbf{2}\right)$, with characteristic absorptions at $\lambda=440$ and $665 \mathrm{~nm}$ and $920 \mathrm{~nm} .{ }^{81}$ On the other hand, a characteristic signature of $\mathrm{TTF}^{2+}$, without any confinementdependent behavior, is observed at $\mathrm{E}^{\mathrm{ox}} \simeq 0.70 \mathrm{~V}$ (i.e. TTF-box ${ }^{4+}$ ) (Figure 5f). This observation suggests a strong repulsion between $\mathrm{TTF}^{2+}$ moieties. Finally, at higher voltage, the spectral signature of the oxidized Ruthenium side panels is observed (Figure $5 \mathrm{~d}$ ) with a red shifting of about $100 \mathrm{~nm}$ compared to RuNaph precursor (Figure 5c). This set of spectroelectrochemical data demonstrates that TTF-box constitutes an original example of a bis-TTF derivative for which interactions occuring at oxidized states (mixed valence and $\pi$ - 
dimer) can be characterized at room temperature, a feature which is allowed by the spatial proximity of both TTF units in the coordination self-assembly.

\section{Conclusion}

We have designed a tetratopic ligand $\mathbf{T T F}(\mathbf{P h P y r})_{4}$ in order to favor the formation of a $\mathrm{M}_{8} \mathrm{~L}_{2}$ cage upon self-assembling with a bis-Ruthenium complex, providing a control over the inter-TTF distance. Whereas the Ru-Ru distance is $8.3 \AA$ within the four pillars of the box, short interplanar $C \cdots C$ and $S \cdots S$ distances of respectively $3.48 \AA$ and $3.83 \AA$ are observed between both TTF units in TTF-box. This short distance results from a severe bending of the facing ligands, which collapse towards the center of the cavity. Electrochemical experiments including spectroelectrochemical measurements clearly show that the two facing TTF units interact upon oxidation, giving rise to an oxidized TTF dimer (TTF-box $\left.{ }^{(\bullet+)} \mathbf{2}\right)$. This observation is imputable to the unique geometry of this $\mathrm{M}_{8} \mathrm{~L}_{2}$ assembly, for which the two TTF units are forced to stack together. TTF-box does not disassemble upon oxidation which attests to its robustness, and allows to reversibly generate up to eight positive charges upon oxidation. Given the strong interest in the recent literature for redox-controlled supramolecular interactions, ${ }^{2}$ and considering the unique molecular design of TTF-box for which both redox units are forced to face, extension of this coordination-driven approach to the design of new related redox-active boxes is under study using alternative ligands and bis-metallic complexes.

\section{Author Contributions}

SK, VCr and OA carried out experiments. EL supervised spectroelectrochemical measurements. MA carried out X-ray diffraction analysis. CM helped in growing crystals. VCa and FA performed HMRS FTCIR measurements. ZV, SG and MS supervised and conceived the project. SG and MS wrote the manuscript. All authors discussed the results and contributed to the final manuscript.

\section{Conflicts of interest}

There are no conflicts to declare

\section{Acknowledgements}

The authors gratefully acknowledge the French Embassy in Kiev (Ukr) and university of Angers for PhD grants (SK and $\mathrm{VCr}$ respectively). They also acknowledge the ASTRAL platform (SFR MATRIX, Univ. Angers) for their assistance in spectroscopic analyses. Finally, the financial support from the National FT-ICR network (FR 3624 CNRS) for conducting the research is gratefully acknowledged.

\section{References}

1. Y. Wang, M. Frasconi and J. F. Stoddart, Introducing Stable Radicals into Molecular Machines, ACS Cent. Sci., 2017, 3, 927.

2. D.-W. Zhang, J. Tian, L. Chen, L. Zhang and Z.-T. Li, Dimerization of Conjugated Radical Cations: An Emerging Non-Covalent Interaction for Self-Assembly, Chem. Asian J., 2015, 10, 56.

3. M. Spruell Jason, in Pure Appl. Chem., 2010, p. 2281.

4. C. Kahlfuss, E. Saint-Aman and C. Bucher, Redox-Controlled Intramolecular Motions Triggered by $\pi$-Dimerization and Pimerization Processes, Wiley Online Library, 2015, 39.

5. M. Hasegawa and M. lyoda, in Organic Redox Systems, John Wiley \& Sons, Inc., Hoboken, NJ, USA, 2016, pp. 89.

6. D. Canevet, M. Sallé, G. Zhang, D. Zhang and D. Zhu, Tetrathiafulvalene (TTF) derivatives: key building-blocks for switchable processes, Chem. Commun., 2009, 2245.

7. S. V. Rosokha and J. K. Kochi, Molecular and Electronic Structures of the Long-Bonded $\pi$-Dimers of Tetrathiafulvalene Cation-Radical in Intermolecular Electron Transfer and in (Solid-State) Conductivity, J. Am. Chem. Soc., 2007, 129, 828.

8. V. Khodorkovsky, L. Shapiro, P. Krief, A. Shames, G. Mabon, A. Gorgues and M. Giffard, Do $\pi$-dimers of tetrathiafulvalene cation radicals really exist at room temperature?, Chem. Commun., 2001, 2736.

9. R. Zaffaroni, E. O. Bobylev, R. Plessius, J. I. van der Vlugt and J. N. H. Reek, How to Control the Rate of Heterogeneous Electron Transfer across the $\operatorname{Rim}$ of $\mathrm{M}_{6} \mathrm{~L}_{12}$ and $\mathrm{M}_{12} \mathrm{~L}_{24}$ Nanospheres, J. Am. Chem. Soc., 2020, 142, 8837.

10. M. Capdevila-Cortada, J. S. Miller and J. J. Novoa, The Origin of the Room-Temperature Stability of $[\mathrm{TTF}]^{\cdot+\ldots}[\mathrm{TTF}]^{\bullet+}$ Long, Multicenter Bonds Found in Functionalized $\pi$-[R-TTF $]_{2}{ }^{2+}$ Dimers Included in the Cucurbit[8]uril Cavity, Chem. Eur. J., 2014, 20, 7784.

11. M. Yoshizawa, K. Kumazawa and M. Fujita, RoomTemperature and Solution-State Observation of the MixedValence Cation Radical Dimer of Tetrathiafulvalene, $\left[(\mathrm{TTF})_{2}\right]^{+\bullet}$, within a Self-Assembled Cage, J. Am. Chem. Soc., 2005, 127, 13456.

12. A. Y. Ziganshina, Y. H. Ko, W. S. Jeon and K. Kim, Stable $\pi-$ dimer of a tetrathiafulvalene cation radical encapsulated in the cavity of cucurbit[8] uril, Chem. Commun., 2004, 806.

13. M. Hasegawa and M. Iyoda, Self-Assembly of Radially $\pi$ Extended Tetrathiafulvalene Tetramers for Visible and Near Infrared Electrochromic Nanofiber, Bull. Chem. Soc. Jpn., 2020, 93, 154.

14. L. Faour, C. Adam, C. Gautier, S. Goeb, M. Allain, E. Levillain, D. Canevet and M. Sallé, Redox-controlled hybridization of helical foldamers, Chem. Commun., 2019, 55, 5743.

15. M. Fumanal, M. Capdevila-Cortada and J. J. Novoa, Understanding room-temperature $\pi$-dimerisation of radical ions: intramolecular $\pi$-[TTF $]_{2}{ }^{2+}$ in functionalised calix[4]arenes, Phys. Chem. Chem. Phys., 2017, 19, 3807.

16. Y. Cotelle, M. Hardouin-Lerouge, S. Legoupy, O. Alévêque, E. Levillain and P. Hudhomme, Glycoluriltetrathiafulvalene molecular clips: on the influence of electronic and spatial properties for binding neutral accepting guests, Beilstein J. Org. Chem., 2015, 11, 1023.

17. M. Fumanal, M. Capdevila-Cortada, J. S. Miller and J. J. Novoa, Keys for the Existence of Stable Dimers of Bistetrathiafulvalene (bis-TTF)-Functionalized Molecular Clips Presenting $[\mathrm{TTF}]^{\circ+\ldots}[\mathrm{TTF}]^{0^{+}}$Long, Multicenter Bonds at Room Temperature, J. Am. Chem. Soc., 2013, 135, 13814. 
M. Hasegawa, K. Daigoku, K. Hashimoto, H. Nishikawa and M. Iyoda, Face-to-Face Dimeric Tetrathiafulvalenes and Their Cation Radical and Dication Species as Models of Mixed Valence and $\pi$-Dimer States, Bull. Chem. Soc. Jpn., 2012, 85, 51.

19. C. Bejger, C. M. Davis, J. S. Park, V. M. Lynch, J. B. Love and J. L. Sessler, Palladium Induced Macrocyclic Preorganization for Stabilization of a Tetrathiafulvalene Mixed-Valence Dimer, Org. Lett., 2011, 13, 4902.

20. J. Lyskawa, M. Sallé, J.-Y. Balandier, F. Le Derf, E. Levillain, M. Allain, P. Viel and S. Palacin, Monitoring the formation of TTF dimers by $\mathrm{Na}^{+}$complexation, Chem. Commun., 2006, 2233.

21. M. Hasegawa, J.-i. Takano, H. Enozawa, Y. Kuwatani and M. Iyoda, Aggregation of star-shaped tris(tetrathiafulvalenylethynyl) benzene in solution and in the solid state, Tetrahedron Lett., 2004, 45, 4109.

22. C. A. Christensen, J. Becher, C. A. Christensen, L. M. Goldenberg and M. R. Bryce, Synthesis and electrochemistry of a tetrathiafulvalene $(\mathrm{TTF})_{21}-\mathrm{glycol}$ dendrimer: intradendrimer aggregation of TTF cation radicals, Chem. Commun., 1998, 509.

23. J. M. Spruell, A. Coskun, D. C. Friedman, R. S. Forgan, A. A. Sarjeant, A. Trabolsi, A. C. Fahrenbach, G. Barin, W. F. Paxton, S. K. Dey, M. A. Olson, D. Benítez, E. Tkatchouk, M. T. Colvin, R. Carmielli, S. T. Caldwell, G. M. Rosair, S. G. Hewage, F. Duclairoir, J. L. Seymour, A. M. Z. Slawin, W. A. Goddard, M. R. Wasielewski, G. Cooke and J. F. Stoddart, Highly stable tetrathiafulvalene radical dimers in [3]catenanes, Nat. Chem., 2010, 2, 870.

24. C. Gourlaouen, S. Vela, S. Choua, M. Berville, J. A. Wytko, J. Weiss and V. Robert, Pairing-up viologen cations and dications: a microscopic investigation of van der Waals interactions, Phys. Chem. Chem. Phys., 2018, 20, 27878.

25. M. Berville, S. Choua, C. Gourlaouen, C. Boudon, L. Ruhlmann, C. Bailly, S. Cobo, E. Saint-Aman, J. Wytko and J. Weiss, Flexible Viologen Cyclophanes: Odd/Even Effects on Intramolecular Interactions, Chemphyschem, 2017, 18, 796.

26. M. Berville, L. Karmazin, J. A. Wytko and J. Weiss, Viologen cyclophanes: redox controlled host-guest interactions, Chem. Commun., 2015, 51, 15772.

27. A. Jana, S. Bähring, M. Ishida, S. Goeb, D. Canevet, M. Sallé, J. O. Jeppesen and J. L. Sessler, Functionalised tetrathiafulvalene- (TTF-) macrocycles: recent trends in applied supramolecular chemistry, Chem. Soc. Rev., 2018, 47, 5614.

28. K. Nielsen, J. O. Jeppesen, N. Thorup and J. Becher, A Pyrrolo-Tetrathiafulvalene Belt and Its TCNQ Complex: Syntheses and X-ray Crystal Structures, Org. Lett., 2002, 4, 1327.

29. G.-Y. Wu, L.-J. Chen, L. Xu, X.-L. Zhao and H.-B. Yang, Construction of supramolecular hexagonal metallacycles via coordination-driven self-assembly: Structure, properties and application, Coord. Chem. Rev., 2018, 369, 39.

30. Y. Lu, H.-N. Zhang and G.-X. Jin, Molecular Borromean Rings Based on Half-Sandwich Organometallic Rectangles, Acc. Chem. Res., 2018, 51, 2148.

31. T. Y. Kim, R. A. S. Vasdev, D. Preston and J. D. Crowley, Strategies for Reversible Guest Uptake and Release from Metallosupramolecular Architectures, Chem. Eur. J, 2018, 24, 14878.
32. M.-M. Gan, J.-Q. Liu, L. Zhang, Y.-Y. Wang, F. E. Hahn and Y.-F. Han, Preparation and Post-Assembly Modification of Metallosupramolecular Assemblies from Poly(NHeterocyclic Carbene) Ligands, Chem. Rev., 2018, 118, 9587.

33. L.-J. Chen and H.-B. Yang, Construction of StimuliResponsive Functional Materials via Hierarchical SelfAssembly Involving Coordination Interactions, Acc. Chem. Res., 2018, 51, 2699.

34. S.-L. Huang, T. S. A. Hor and G.-X. Jin, Metallacyclic assembly of interlocked superstructures, Coord. Chem. Rev., 2017, 333, 1.

35. L. R. Holloway, P. M. Bogie and R. J. Hooley, Controlled selfsorting in self-assembled cage complexes, Dalton Trans., 2017, 46, 14719.

36. L.-J. Chen, H.-B. Yang and M. Shionoya, Chiral metallosupramolecular architectures, Chem. Soc. Rev., 2017, 46, 2555.

37. A. Casini, B. Woods and M. Wenzel, The Promise of SelfAssembled 3D Supramolecular Coordination Complexes for Biomedical Applications, Inorg. Chem., 2017, 56, 14715. 38. W. M. Bloch and G. H. Clever, Integrative self-sorting of coordination cages based on 'naked' metal ions, Chem. Commun., 2017, 53, 8506

39. W. Wang, Y.-X. Wang and H.-B. Yang, Supramolecular transformations within discrete coordination-driven supramolecular architectures, Chem. Soc. Rev., 2016, 45, 2656.

40. M. L. Saha, X. Yan and P. J. Stang, Photophysical Properties of Organoplatinum(II) Compounds and Derived SelfAssembled Metallacycles and Metallacages: Fluorescence and its Applications, Acc. Chem. Res., 2016, 49, 2527.

41. M. Frank, M. D. Johnstone and G. H. Clever, Interpenetrated Cage Structures, Chem. Eur. J., 2016, 22, 14104.

42. S. Zarra, D. M. Wood, D. A. Roberts and J. R. Nitschke, Molecular containers in complex chemical systems, Chem. Soc. Rev., 2015, 44, 419.

43. L. Xu, Y.-X. Wang and H.-B. Yang, Recent advances in the construction of fluorescent metallocycles and metallocages via coordination-driven self-assembly, Dalton Trans., 2015, 44, 867.

44. L. Xu, Y. X. Wang, L. J. Chen and H. B. Yang, Construction of multiferrocenyl metallacycles and metallacages via coordination-driven self-assembly: from structure to functions, Chem. Soc. Rev., 2015, 44, 2148.

45. D.-H. Qu, Q.-C. Wang, Q.-W. Zhang, X. Ma and H. Tian, Photoresponsive Host-Guest Functional Systems, Chem. Rev., 2015, 115, 7543.

46. A. J. McConnell, C. S. Wood, P. P. Neelakandan and J. R. Nitschke, Stimuli-Responsive Metal-Ligand Assemblies, Chem. Rev., 2015, 115, 7729.

47. M. Liu, L. Zhang and T. Wang, Supramolecular Chirality in Self-Assembled Systems, Chem. Rev., 2015, 115, 7304.

48. J. J. Henkelis and M. J. Hardie, Controlling the assembly of cyclotriveratrylene-derived coordination cages, Chem. Commun., 2015, 51, 11929.

49. Z. He, W. Jiang and C. A. Schalley, Integrative self-sorting: a versatile strategy for the construction of complex supramolecular architecture, Chem. Soc. Rev., 2015, 44, 779.

50. T. R. Cook and P. J. Stang, Recent Developments in the Preparation and Chemistry of Metallacycles and 
Metallacages via Coordination, Chem. Rev., 2015, 115, 7001.

51. R. Chakrabarty, P. S. Mukherjee and P. J. Stang, Supramolecular coordination: self-assembly of finite twoand three-dimensional ensembles, Chem. Rev., 2011, 111, 6810.

52. D. Fink, N. Orth, M. Linseis, I. Ivanović-Burmazović and R. F. Winter, Structural Versatility and Supramolecular Isomerism in Redox-Active Tetra- and Hexaruthenium Macrocycles, Eur. J. Inorg. Chem., 2020, 2020, 2816.

53. D. Fink, N. Orth, V. Ebel, F. S. Gogesch, A. Staiger, M. Linseis, I. Ivanović-Burmazović and R. F. Winter, SelfAssembled Redox-Active Tetraruthenium Macrocycles with Large Intracyclic Cavities, Organometallics, 2020, 39, 1861.

54. R. Plessius, V. Deij, J. N. H. Reek and J. I. van der Vlugt, Redox-Active Supramolecular Heteroleptic $\mathrm{M}_{4} \mathrm{~L}_{2} \mathrm{~L}_{2}$ Assemblies with Tunable Interior Binding Site, Chem. Eur. J., 2020, 26, 13241.

55. R. Plessius, N. Orth, I. Ivanović-Burmazović, M. A. Siegler, J. N. H. Reek and J. I. van der Vlugt, Reversible multi-electron storage in dual-site redox-active supramolecular cages, Chem. Commun., 2019, 55, 12619.

56. R. F. Winter, The molecular electrochemistry of metalorganic metallamacrocycles, Curr. Opin. Electrochem. 2018, 8, 14.

57. K. Yazaki, S. Noda, Y. Tanaka, Y. Sei, M. Akita and M. Yoshizawa, An $\mathrm{M}_{2} \mathrm{~L}_{4}$ Molecular Capsule with a Redox Switchable Polyradical Shell, Angew. Chem. Int. Ed., 2016, 55, 15031.

58. V. Croué, S. Goeb and M. Sallé, Metal-driven self-assembly: the case of redox-active discrete architectures, Chem. Commun., 2015, 51, 7275.

59. G. Szalóki, S. Krykun, V. Croué, M. Allain, Y. Morille, F. Aubriet, V. Carré, Z. Voitenko, S. Goeb and M. Sallé, RedoxDriven Transformation of a Discrete Molecular Cage into an Infinite 3D Coordination Polymer, Chem. Eur. J., 2018, 24, 11273.

60. G. Szalóki, V. Croué, V. Carré, F. Aubriet, O. Alévêque, E. Levillain, M. Allain, J. Arago, E. Orti, S. Goeb and M. Sallé, Controlling the Host-Guest Interaction Mode through a Redox Stimulus, Angew. Chem. Int. Ed., 2017, 56, 16272.

61. G. Szalóki, V. Croué, M. Allain, S. Goeb and M. Sallé, Neutral versus polycationic coordination cages: a comparison regarding neutral guest inclusion, Chem. Commun., 2016, 52, 10012 .

62. V. Croué, S. Goeb, G. Szalóki, M. Allain and M. Sallé, Reversible Guest Uptake/Release by Redox-Controlled Assembly/Disassembly of a Coordination Cage, Angew. Chem. Int. Ed., 2016, 55, 1746.

63. S. Bivaud, S. Goeb, V. Croué, M. Allain, F. Pop and M. Sallé, Tuning the size of a redox-active tetrathiafulvalene-based self-assembled ring, Beilstein J. Org. Chem., 2015, 11, 966.

64. S. Bivaud, S. Goeb, V. Croué, P. I. Dron, M. Allain and M. Sallé, Self-Assembled Containers Based on Extended Tetrathiafulvalene, J. Am. Chem. Soc., 2013, 135, 10018.

65. S. Krykun, M. Dekhtiarenko, D. Canevet, V. Carré, F. Aubriet, E. Levillain, M. Allain, Z. Voitenko, M. Sallé and S. Goeb, Metalla-Assembled Electron-Rich Tweezers: RedoxControlled Guest Release Through Supramolecular Dimerization, Angew. Chem. Int. Ed., 2020, 59, 716.

66. V. Croué, S. Krykun, M. Allain, Y. Morille, F. Aubriet, V. Carré, Z. Voitenko, S. Goeb and M. Sallé, A self-assembled
$\mathrm{M}_{2} \mathrm{~L}_{4}$ cage incorporating electron-rich 9-(1,3-dithiol-2ylidene)fluorene units, New J. Chem., 2017, 41, 3238.

67. M. Dekhtiarenko, S. Krykun, V. Carré, F. Aubriet, D. Canevet, M. Allain, Z. Voitenko, M. Sallé and S. Goeb, Tuning the structure and the properties of dithiafulvene metalla-assembled tweezers, Org. Chem. Front., 2020, 7, 2040.

68. V. Vajpayee, S. Bivaud, S. Goeb, V. Croué, M. Allain, B. V. Popp, A. Garci, B. Therrien and M. Sallé, Electron-Rich Arene-Ruthenium Metalla-architectures Incorporating Tetrapyridyl-Tetrathiafulvene Donor Moieties, Organometallics, 2014, 33, 1651.

69. S. Goeb, S. Bivaud, V. Croué, V. Vajpayee, M. Allain and M. Sallé, A Self-Assembled Electro-Active $M_{8} \mathrm{~L}_{4}$ Cage Based on Tetrathiafulvalene Ligands, Materials, 2014, 7, 611.

70.

B. Therrien, Arene Ruthenium Cages: Boxes Full of Surprises, Eur. J. Inorg. Chem., 2009, 2445.

71. Y. Mitamura, H. Yorimitsu, K. Oshima and A. Osuka, Straightforward access to aryl-substituted tetrathiafulvalenes by palladium-catalysed direct $\mathrm{C}-\mathrm{H}$ arylation and their photophysical and electrochemical properties, Chem. Sci., 2011, 2, 2017.

72. Y. Wang, D. L. Frattarelli, A. Facchetti, E. Cariati, E. Tordin, R. Ugo, C. Zuccaccia, A. Macchioni, S. L. Wegener, C. L. Stern, M. A. Ratner and T. J. Marks, Twisted $\pi$-Electron System Electrooptic Chromophores. Structural and Electronic Consequences of Relaxing Twist-Inducing Nonbonded Repulsions, J Phys. Chem. C, 2008, 112, 8005.

73. L. Avram and Y. Cohen, Diffusion NMR of molecular cages and capsules, Chem. Soc. Rev., 2015, 44, 586.

Chemical oxidation of TTF-box results in cage degradation. J. Mattsson, P. Govindaswamy, A. K. Renfrew, P. J. Dyson, P. Štěpnička, G. Süss-Fink and B. Therrien, Synthesis, Molecular Structure, and Anticancer Activity of Cationic Arene Ruthenium Metallarectangles, Organometallics, 2009, 28, 4350.

76. H. Jung, A. Dubey, H. J. Koo, V. Vajpayee, T. R. Cook, H. Kim, S. C. Kang, P. J. Stang and K.-W. Chi, Self-Assembly of Ambidentate Pyridyl-Carboxylate Ligands with Octahedral Ruthenium Metal Centers: Self-Selection for a SingleLinkage Isomer and Anticancer-Potency Studies, Chem. Eur. J., 2013, 19, 6709.

77. E. Orhan, A. Garci and B. Therrien, Flexible arene ruthenium metalla-prisms, Inorg. Chim. Acta, 2015, 438, 5.

78. H. V. Schröder and C. A. Schalley, Tetrathiafulvalene - a redox-switchable building block to control motion in mechanically interlocked molecules, Beilstein J. Org. Chem., 2018, 14, 2163.

79. The narrow and low intensity band observed at ca. 1400 $\mathrm{nm}$ that emerges while forming the radical cation states is located in an area where the detector is weakly sensitive. This band which is observed in all the spectra, is assigned to artifacts and will not be commented further.

80. One should note that the instrument detection range $(\lambda=$ $400-1550 \mathrm{~nm}$ ) did not allow for observing the weak and broad band in the IR region characteristic of the valence mixed state (reference 81).

81. H. V. Schröder, A. Mekic, H. Hupatz, S. Sobottka, F. Witte, L. H. Urner, M. Gaedke, K. Pagel, B. Sarkar, B. Paulus and C. A. Schalley, Switchable synchronisation of pirouetting motions in a redox-active [3]rotaxane, Nanoscale, 2018, 10, 21425. 